\title{
European Prospective Investigation into Cancer and Nutrition (EPIC) calibration study: rationale, design and population characteristics
}

N Slimani ${ }^{1, *}$, R Kaaks $^{2}$, P Ferrari ${ }^{1}$, C Casagrande ${ }^{1}$, F Clavel-Chapelon ${ }^{3}$, G Lotze ${ }^{4}$ A Kroke ${ }^{5}$, D Trichopoulos ${ }^{6,7}$, A Trichopoulou 7 , C Lauria ${ }^{8}, M$ Bellegotti $^{9}, M C$ Ocké $^{10}$, PHM Peeters ${ }^{11}$, D Engeset ${ }^{12}$, E Lund ${ }^{12}$, A Agudo $^{13}, \mathrm{~N}^{2}$ Larrañaga ${ }^{14}$, I Mattisson ${ }^{15}$, C Andren ${ }^{15}$, I Johansson ${ }^{16}, \mathrm{G}$ Davey ${ }^{17}$, AA Welch $^{18}$, K Overvad ${ }^{19}$, A Tjønneland ${ }^{20}$, WA van Staveren ${ }^{21}$, R Saracci $^{1}$ and E Riboli ${ }^{1}$

'Unit of Nutrition and Cancer, International Agency for Research on Cancer (IARC-WHO), 150 cours AlbertThomas, 69372 Lyon Cedex 08, France: ${ }^{2}$ Hormones and Cancer Group, IARC-WHO, Lyon, France: ${ }^{3}$ INSERM, U52 1, Institute Gustave Roussy, Villejuif, France: ${ }^{4}$ Division of Clinical Epidemiology, German Cancer Research Centre, Heidelberg, Germany: ${ }^{5}$ German Institute of Human Nutrition, Potsdam-Rehbrücke, Germany: ${ }^{6}$ Department of Epidemiology, Harvard School of Public Health, Boston, MA, USA: ${ }^{7}$ Department of Hygiene and Epidemiology, School of Medicine, University of Athens, Greece: ${ }^{8}$ Cancer Registry, 'Civile - M.P. Arezzo' Hosptial, Ragusa, Italy: ${ }^{9}$ Epidemiology Unit, National Cancer Institute, Milan, Italy: ${ }^{10}$ Department for Chronic Diseases Epidemiology, National Institute for Public Health and the Environment, Bilthoven, The Netherlands: " 1 Julius Center for General Practice and Patient Oriented Research, University of Utrecht, The Netherlands: ${ }^{12}$ Institute of Community Medicine, University of Tromsø, Norway: ${ }^{13}$ Department of Epidemiology, Catalan Institute of Oncology, Barcelona, Spain:

${ }^{14}$ Public Health Division of Gipuzkoa, Department of Health of the Basque Government, San Sebastian, Spain:

${ }^{15}$ Department of Medicine, Surgery and Orthopaedics, Lund University, Malmö, Sweden: ${ }^{16}$ Department of Nutritional Research, University of Umeå, Sweden: ${ }^{17}$ Cancer Research UK, Epidemiology Unit, University of Oxford, UK: ${ }^{18}$ Institute of Public Health, School of Clinical Medicine, University of Cambridge, UK: ${ }^{19}$ Institute of Epidemiology and Social Medicine, University of Aarhus, Denmark: ${ }^{20}$ Institute of Cancer Epidemiology, Danish Cancer Society, Copenhagen, Denmark: ${ }^{21}$ Department of Human Nutrition and Epidemiology, Wageningen Agricultural University, The Netherlands

\begin{abstract}
The European Prospective Investigation into Cancer and Nutrition (EPIC), which covers a large cohort of half a million men and women from 23 European centres in 10 Western European countries, was designed to study the relationship between diet and the risk of chronic diseases, particularly cancer. Information on usual individual dietary intake was assessed using different validated dietary assessment methods across participating countries. In order to adjust for possible systematic over- or underestimation in dietary intake measurements and correct for attenuation bias in relative risk estimates, a calibration approach was developed. This approach involved an additional dietary assessment common across study populations to re-express individual dietary intakes according to the same reference scale. A single 24-hour diet recall was therefore collected, as the EPIC reference calibration method, from a stratified random sample of 36900 subjects from the entire EPIC cohort, using a software program (EPIC-SOFT) specifically designed to standardise the dietary measurements across study populations. This paper describes the design and populations of the calibration sub-studies set up in the EPIC centres. In addition, to assess whether the calibration sub-samples were representative of the entire group of EPIC cohorts, a series of subjects' characteristics known possibly to influence dietary intakes was compared in both population groups. This was the first time that calibration sub-studies had been set up in a large multi-centre European study. These studies showed that, despite certain inherent methodological and logistic constraints, a study design such as this one works relatively well in practice. The average response in the calibration study was $78.3 \%$ and ranged from $46.5 \%$ to $92.5 \%$. The calibration population differed slightly from the overall cohort but the differences were small for most characteristics and centres. The overall results suggest that, after adjustment for age, dietary intakes estimated from calibration samples can reasonably be interpreted as representative of the main cohorts in most of the EPIC centres.
\end{abstract}

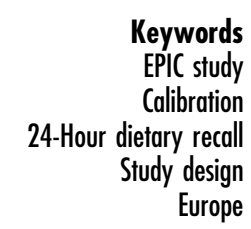


Compared with retrospective case-control or ecological studies, large multi-centre prospective studies offer major advantages for investigating the relationship between diet and other lifestyle factors and risk of chronic diseases ${ }^{1-3}$. These studies are designed to increase the statistical power to detect an association between diet and disease by including large study populations varying both in the type of dietary patterns and cancer incidence rates, thus increasing the heterogeneity of both exposure and disease outcomes ${ }^{4}$. However, multi-centre studies also raise relatively new statistical and methodological issues for the comparison and pooled analysis of dietary intake data collected from large heterogeneous populations with wide differences in food consumption, language and sociocultural characteristics. In particular, the inherent difficulty of estimating and comparing individuals' usual dietary intakes is amplified in large multi-centre studies, where dietary questionnaires often differ across study populations in order to capture the specific local diets ${ }^{5}$. The magnitude and nature of systematic and random errors in dietary intake measurements may thus vary across study populations and distort the estimation and interpretation of the overall relationship between diet and disease when all cohorts are combined.

Several authors ${ }^{6-10}$ have proposed the use of a calibration approach in large nutritional studies. The purpose of such calibration studies is twofold: first, at the population level, to adjust for systematic over- and underestimation of the true mean dietary intakes in each centre; second, at the individual level, to attempt to correct for attenuation bias in relative risk due to random errors in dietary measurements. For calibration at the population level, where emphasis is on unbiased estimates of mean intake, calibration can be achieved by applying, in addition to the dietary questionnaires, a second highly standardised dietary method in a representative subsample from each cohort as a common reference measurement across study populations. In its simplest definition, calibration means re-expressing the individual dietary measurements by means of centre-specific scaling factors. At the individual level, correction for regression dilution can only be fully achieved if the measurement errors of the second dietary assessment instrument are independent from the errors of the main instrument used in the entire cohort.

Although this complex study design initiates a new generation of large nutritional cohorts with nested calibration sub-studies, there is still little experience on how to set up such studies in practice ${ }^{11,12}$. This paper describes the design of the calibration sub-studies within the European Prospective Investigation into Cancer and Nutrition (EPIC), a network of prospective cohort studies involving 23 European centres from 10 Western European countries (France, Italy, Spain, the UK, Germany, The Netherlands, Greece, Sweden, Denmark and Norway). Among the most important features of EPIC are its size, geographical distribution and heterogeneity of the dietary patterns and other lifestyle and socio-cultural characteristics of the study populations. Information on usual diet, lifestyle, environmental factors and anthropometry was collected from each individual at baseline, as well as one blood sample. Information on usual individual dietary intakes was assessed using different dietary history questionnaires, food-frequency questionnaires or a modified dietary history ${ }^{13}$ developed and validated in each participating country ${ }^{14-16}$. More details on the EPIC study design, the study cohort populations, the individual information collected and the EPIC biological bank are given elsewhere in this supplement ${ }^{17}$.

In addition, a single 24-hour dietary recall (24-HDR) was collected from a sub-sample of 36900 individuals, to be used as the EPIC reference calibration method. Computerised 24-hour dietary recall interview software (EPICSOFT) was developed to standardise dietary intakes reported across the EPIC centres and increase the likelihood that measurement errors will be of a similar magnitude and nature in all study centres. The concept of standardisation and the structure of the EPIC-SOFT software are described in detail by Slimani et al. ${ }^{18,19}$.

This paper describes the design and populations of the calibration sub-studies set up in the centres participating in the EPIC study. In addition, in order to assess whether the calibration sub-samples were representative of the overall group of EPIC cohorts, a series of subjects' characteristics known possibly to influence dietary intakes was compared in both population groups.

\section{Study protocol}

\section{Sampling procedures}

The EPIC study populations were not chosen to provide representative samples. Recruitment was determined by practical and logistic considerations in order to obtain high participation and long-term follow-up from the study participants ${ }^{17}$. These study populations represent heterogeneous groups and were population-based (Bilthoven, The Netherlands; Greece; Germany; Sweden; Denmark; Norway; Cambridge and a small part of the Oxford cohort from the UK; Spain; Italy) or participants in breast screening (Utrecht, The Netherlands; Florence, Italy) or teachers and school workers in France. In Oxford, most of the cohort $(\sim 87 \%)$ was recruited among subjects with an interest in health and/or vegetarian eating habits who were either self-defined vegans (i.e. consumed no animal products), ovo-lacto vegetarians, fish eaters (i.e. consumers of fish but not meat) or meat eaters. Blood donors were also recruited in different proportions in certain Italian and Spanish centres. In France, Norway, Utrecht (The Netherlands) and Naples (Italy) only women were recruited.

The calibration population was defined as a random sample from each of these cohorts, weighted according to 
the cumulative numbers of cancer cases expected over 10 years of follow-up per gender and 5-year age stratum. The sample sizes were chosen to provide calibration at both the individual and population level, even though it was recognised that the 24-hour dietary recall and the main dietary assessment instrument would not have fully independent error structures. A total of about 4000 24hour dietary recalls, equivalent to a single, large random sample drawn from each full country cohort, was recommended per country, according to calculations detailed elsewhere ${ }^{20}$. This sample size was achieved in most countries, except in the UK (1117), Norway (1819) and Greece (2930), and represents, according to the age distribution and size of the cohort, between $5 \%$ and $12 \%$ of the study population in each national cohort, except in the UK $(\sim 1.5 \%)$. In Norway, the calibration sample size requirement was smaller because lower numbers of cancers are expected from the relatively young cohort of women only. In Greece, a 10\% representative sample of the entire cohort (28572) was recruited all over Greece including Athens. In the UK, the sample size of 1117 was chosen to provide population-level calibration, i.e. the sample size was calculated to give a sufficiently accurate estimation of mean intakes. Much of the UK cohort has already completed a second dietary instrument, a 7-day diet diary that included an interviewed 24-hour recall as a component, which could be used for (within-cohort) individual-level calibration should it be required.

In certain countries, the calibration population was sampled strictly at random, particularly when the age distributions were quite narrow, as in Norway (e.g. $49.3 \pm$ 4.3 years). In France, where the study population was scattered all over the country and it was not possible to interview subjects living far from large urban areas, cluster sampling was used: contiguous, sparsely populated administrative regions were grouped into seven geographical areas in which the subjects could more easily be sampled randomly and approached for home visits or invited to a local centre for the 24-HDR interview. Using cluster sampling, a higher probability of being sampled was given to clusters with a higher number of subjects and vice versa.

In addition, the sampling procedures were defined as having an equal distribution of season and day of interview, to control for possible day-to-day and seasonal variations in dietary consumption. Although in Spain, for example, the response rates obtained during the pilot phase were as high for interviews on Saturdays as for the other days of the week, other countries such as France and The Netherlands experienced high refusal rates for Saturday interviews. In addition, certain examination centres were closed or interviewers did not work during the weekends (e.g. Denmark, The Netherlands). Because of these constraints, alternative methods were considered to approach and interview the subjects during the weekend (i.e. to recall the Saturdays and Fridays). In some instances, interviews on Fridays and Saturdays were collected 48 hours later instead of the following day, and interviews at home were proposed to increase the participation rate. Such methods were rarely used for other days of the week, unless it was impossible to interview on the given sampled day or perform the interview at the examination centre.

\section{Logistics used to set up the EPIC calibration sub-studies}

The EPIC calibration fieldwork was conducted over a 5year period between March 1995 and June 2000. A pilot phase was started initially in France (Rhône-Alpes), Spain (Basque Country) and The Netherlands in order to test the first version of EPIC-SOFT and the overall logistics. It was then extended to the other countries/centres according to the availability of country-specific EPIC-SOFT versions and the date of entry in EPIC. In order to have representative calibration sub-populations, the calibration study lasted until the end of the EPIC baseline recruitment. Depending on the country, it took between 10 and 31 months to collect the interviews sampled to cover both day-to-day and seasonal variations. Overall it took longer to perform the required dietary interviews in countries where several local, geographically distant centres were involved (e.g. France, Italy or Spain), where total population coverage was attempted (Greece) and where different study populations, study designs and recruitment methods were used. The time required for conducting the calibration fieldwork was not strictly related to the total number of interviews, because at least 1 year was needed to cover all seasons. It is also interesting to note, for example, that the Nordic countries, which joined EPIC later, benefited from more advanced methodology (i.e. the overall logistics and EPIC-SOFT programs were fully developed and tested), which allowed them to complete the interviews more quickly than other countries.

Table 1 summarises the methods of recruitment and the localisation of the 24-HDR interviews performed in the EPIC centres. Whenever possible, subjects were recruited to the calibration study 'by surprise', when they came for their first baseline examination. The dietary interview was then performed 30-40 minutes immediately after their baseline examination. It was anticipated that this recruitment approach would give a higher participation rate, as subjects would not have to return to the examination centres. This method was used for $84-100 \%$ of the subjects in Paris and the surrounding area (Ile-de-France), Potsdam (Germany), The Netherlands and Denmark, and to a lesser extent in other French centres (i.e. Rhône-Alpes, 36\%; Bretagne/Pays-de-Loire, 28\%), Heidelberg (Germany; 62\%) and Ragusa (Italy; 42\%).

In the other centres, the subjects had either been enrolled before joining EPIC or had already been invited for the baseline examination when the calibration study was started. The subjects randomly selected to participate 


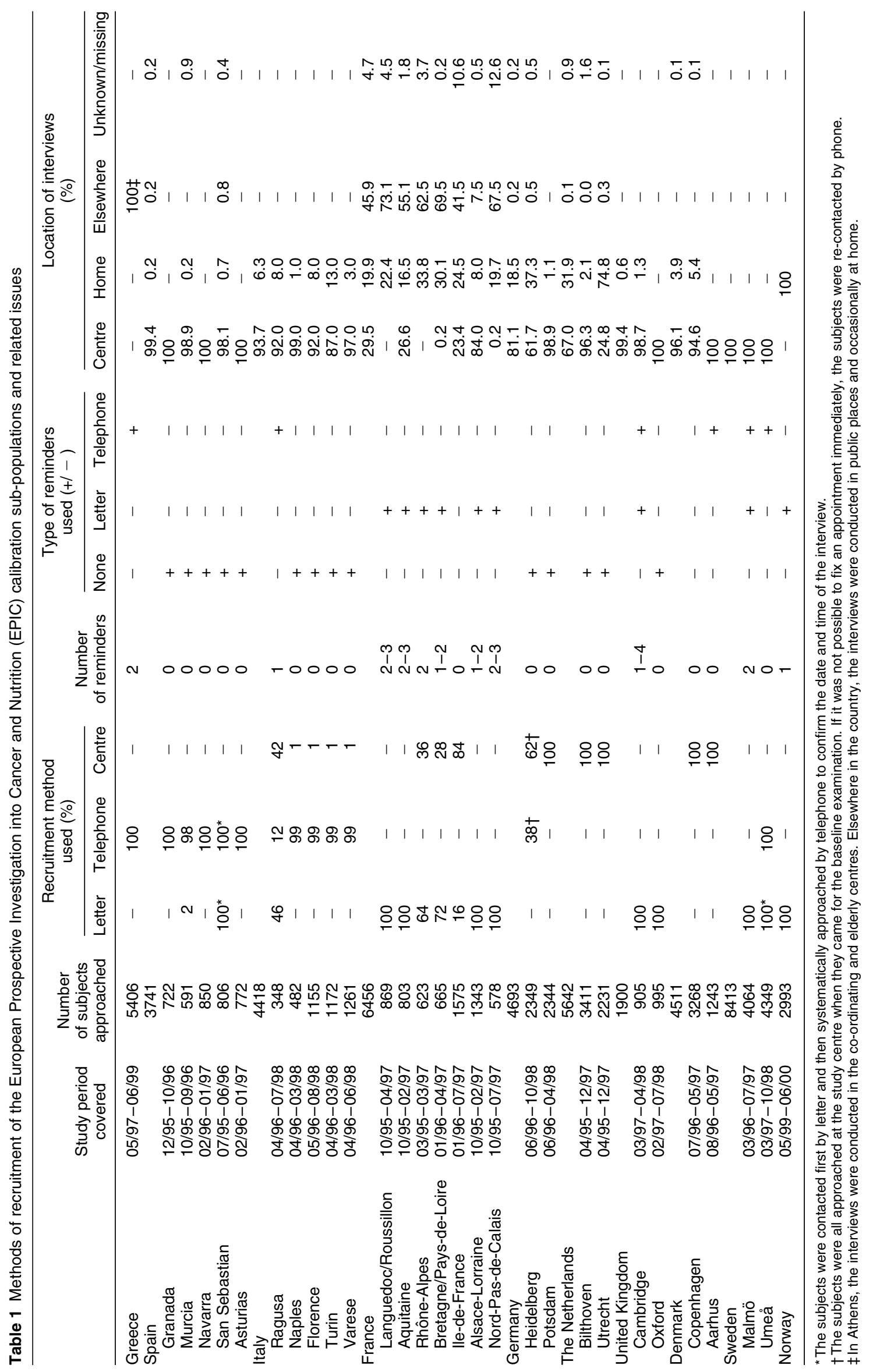


in the calibration study were then re-contacted either by letter (France, UK, Norway and Sweden) or by telephone (Spain, Italy (except Ragusa) and Greece). In contrast to recruitment at baseline, the subjects re-invited by letter or telephone were asked to return to provide further information but were not informed about the type of dietary method or time period to which it referred (i.e. the previous day). This precaution was taken in order to avoid changes in usual dietary habits and bias during the recalled dietary interview. According to what best suited the subjects and the local facilities available, the face-toface 24-HDR interview was performed at the local research centre or at home, particularly if the people were living far from the research institute. In France, the overall study was co-ordinated from Paris and local authorities and cancer leagues made rooms available to conduct the dietary interviews (e.g. schools, town halls, local cancer leagues). In Greece, where it was particularly difficult to recruit local volunteers outside Athens, mobile units were used. In Norway, where the interviews were conducted by telephone, the subjects were all interviewed at home. According to the country and method of recruitment used, one to four reminders were sent when subjects did not reply.

\section{Exclusions and inclusions of subjects from the 24-HDR dataset}

The information reported in the following tables was calculated from the final 24-HDR dataset $(n=35955)$ obtained after further 24-HDR exclusions or inclusions from the original sample. We excluded $358(\sim 1 \%)$ interviews locally, mainly because of technical problems with the software during the interview or because subjects were not properly randomised or excluded from the EPIC cohort for other reasons (e.g. incomplete data). Subjects under 35 and over 74 years of age (who were present only in a few EPIC cohorts) were excluded from the dataset before statistical analyses. This represented a total of 945 subjects, mainly from Bilthoven ( 583 young people) and Greece (244, mainly elderly people).

In addition, $357(<1 \%$ of the total final sample $)$ subjects not originally sampled were added to the calibration population (29 subjects from Naples, 130 from Potsdam, 46 from Cambridge, 152 from Oxford). These subjects were involved in other EPIC cross-sectional or validation studies on urinary or blood biological markers and diet and most of them were participants sampled from the calibration sub-populations. Apart from Oxford, all have an EPIC-SOFT 24-HDR measurement collected in previous EPIC pilot studies. In Oxford, the 152 subjects added, essentially vegans and vegetarians, were not part of the representative sample initially selected for the calibration study, had no EPIC-SOFT 24-hour dietary recall measurements and were difficult to re-contact because they were living throughout the UK. It was therefore decided to sample randomly one day from the 7-day records, collected at baseline in the UK, in addition to the EPIC food-frequency questionnaire, and enter them using EPICSOFT as a data-entry system (i.e. using the same rules as during a classic face-to-face interview).

\section{Redefinition of the EPIC centres}

With a view to the final statistical analyses, we decided to redefine the centres and geographical regions used to set up the field calibration studies in France, the UK and Norway and reported in Tables 1 and 2. In France, the seven geographical regions initially set up to facilitate the calibration field study were reduced, by clustering the 95 French 'départements', to four geographical regions more representative of the different dietary patterns existing across the country (i.e. North-east, North-west, South and South coast). The cohort of subjects recruited from the general population both in Cambridge and Oxford via general practitioners was grouped together ('general population group'). The UK 'health-conscious' group recruited by post was considered as a separate population group involving heterogeneous sub-populations of vegans, vegetarians, fish eaters and meat eaters. In Norway, it was decided to subdivide the study populations scattered all over the country into coastal (North \& West) and inland (South \& East) regions. The Dutch coordinating centre 'Bilthoven' covers three towns (Amsterdam, Doetinchem, Maastricht), where the subjects were recruited. In total, 27 centres were finally used for the analyses of the EPIC calibration dietary data and for presenting the results reported in Tables 3-9. These include administrative centres and geographical regions in France and Norway, but for convenience the term 'centre' is used for both.

\section{Participation rates, general characteristics and representativeness of the EPIC calibration sub-populations}

\section{Participation rates in the EPIC calibration sub-studies}

The participation rates in the calibration sub-studies obtained in the different EPIC administrative centres are reported in Table 2 . These calculations were obtained before any of the exclusions or additions discussed previously. At the country level, they ranged from 91.6\% (Germany) to $54.2 \%$ (Greece), and seven countries out of 10 had a participation rate of $\sim 75 \%$ or more (Sweden, France, The Netherlands, Italy, Spain, Denmark, Germany). The response rate was about $60 \%$ for the general population in Norway and the UK, and lower in Greece (54.2\%) and in the 'health-conscious' sub-cohort from Oxford (46.5\%).

In Germany, Denmark and the general population in the UK, no differences were observed in the response rates across centres from the same country. In contrast, in France, a higher rate was observed in Ile-de-France, where 
Table 2 Participation rates obtained from the European Prospective Investigation into Cancer and Nutrition (EPIC) centres and countries*

\begin{tabular}{|c|c|c|c|c|c|c|}
\hline \multirow[b]{2}{*}{ Country and centre } & \multirow{2}{*}{$\begin{array}{c}\text { Number of } \\
\text { subjects selected } \\
\text { to be approached }\end{array}$} & \multirow{2}{*}{$\begin{array}{l}\text { Number } \\
\text { of subjects } \\
\text { interviewed }\end{array}$} & \multirow{2}{*}{$\begin{array}{l}\text { Participation } \\
\text { rate (\%) }\end{array}$} & \multicolumn{3}{|c|}{ Non-response } \\
\hline & & & & Active (\%) & Passive (\%) & Total (\%) \\
\hline Greece & 5406 & 2930 & 54.2 & 15.3 & 30.5 & 45.8 \\
\hline Spain & 3741 & 3222 & 86.1 & 9.2 & 4.6 & 13.9 \\
\hline Granada & 722 & 515 & 71.3 & 24.7 & 4.0 & 28.7 \\
\hline Murcia & 591 & 548 & 84.1 & 3.4 & 3.9 & 7.3 \\
\hline Navarra & 850 & 715 & 91.1 & 7.8 & 8.1 & 15.9 \\
\hline San Sebastian & 806 & 734 & 86.1 & 5.2 & 3.7 & 8.9 \\
\hline Asturias & 772 & 710 & 92.0 & 5.2 & 2.8 & 8.0 \\
\hline Italy & 4418 & 3961 & 89.7 & 7.2 & 3.1 & 10.3 \\
\hline Ragusa & 348 & 306 & 87.9 & 6.7 & 5.4 & 12.1 \\
\hline Naples & 482 & 403 & 83.6 & 12.4 & 4.0 & 16.4 \\
\hline Florence & 1155 & 1058 & 91.6 & 7.1 & 1.3 & 8.4 \\
\hline Turin & 1172 & 1069 & 91.2 & 5.4 & 3.4 & 8.8 \\
\hline Varese & 1261 & 1125 & 89.2 & 7.2 & 3.6 & 10.8 \\
\hline France & 6456 & 4854 & 75.2 & 20.5 & 4.3 & 24.8 \\
\hline Languedoc/Roussillon & 869 & 625 & 72.0 & 22.5 & 5.5 & 28.0 \\
\hline Aquitaine & 578 & 443 & 76.6 & 19.2 & 4.2 & 23.4 \\
\hline Rhône-Alpes & 1575 & 1018 & 64.6 & 33.3 & 6.3 & 39.6 \\
\hline Bretagne/Pays-de-Loire & 803 & 635 & 79.1 & 15.2 & 4.6 & 19.8 \\
\hline Ile-de-France & 1343 & 1201 & 89.4 & 9.2 & 1.7 & 10.9 \\
\hline Alsace-Lorraine & 665 & 480 & 72.2 & 22.6 & 5.2 & 27.8 \\
\hline Nord-Pas-de-Calais & 623 & 452 & 72.6 & 25.0 & 2.4 & 27.4 \\
\hline Germany & 4693 & 4299 & 91.6 & 8.2 & 0.2 & 8.4 \\
\hline Heidelberg & 2344 & 2126 & 90.7 & 8.9 & 0.4 & 9.3 \\
\hline Potsdam & 2349 & 2173 & 92.5 & 7.5 & - & 7.5 \\
\hline The Netherlands & 5642 & 4585 & 81.4 & 9.7 & 8.9 & 18.6 \\
\hline Bilthoven & 3411 & 2708 & 79.4 & 10.7 & 9.9 & 20.6 \\
\hline Utrecht & 2231 & 1877 & 84.1 & 8.1 & 7.8 & 15.6 \\
\hline United Kingdom & 1900 & 1117 & 59.0 & 30.0 & 11.0 & 41.0 \\
\hline Cambridge & 905 & 547 & 60.4 & 30.2 & 9.4 & 39.6 \\
\hline Oxford: general population & 640 & 405 & 63.3 & 20.9 & 15.8 & 36.7 \\
\hline Oxford: 'health-conscious' & 355 & 165 & 46.5 & 50.7 & 2.8 & 53.5 \\
\hline Denmark & 4511 & 3919 & 86.9 & 13.1 & - & 13.1 \\
\hline Copenhagen & 3268 & 2842 & 87.0 & 13.0 & - & 13.0 \\
\hline Aarhus & 1243 & 1077 & 86.6 & 13.4 & - & 13.4 \\
\hline Sweden & 8413 & 6195 & 73.6 & 20.4 & 5.9 & 26.3 \\
\hline Malmö & 4064 & 3132 & 77.1 & 19.0 & 3.9 & 22.9 \\
\hline Umeå† & 4349 & 3063 & 70.4 & 21.8 & 7.8 & 29.6 \\
\hline Norway & 2993 & 1819 & 60.8 & 24.0 & 15.2 & 39.2 \\
\hline
\end{tabular}

*Estimates obtained before any exclusion/addition of subjects.

† One hundred and forty-nine individuals were excluded due to a mix-up of food-frequency questionnaires.

the subjects were interviewed immediately after the baseline examination, than in other centres where study participants were re-invited for interviews sometimes more than 2 years afterwards. Within Italy and Spain, lower participation rates were reported in southern centres (Naples and Ragusa, Granada). In the UK, the rate was about $25 \%$ lower among the 'health-conscious' group (46.5\%) compared with the general population group, both in Cambridge and Oxford (60.4\% and 63.3\%, respectively). One possible explanation is that the 'healthconscious' group's initial participation in EPIC was solely by post, so participation in the 24-HDR was their first visit to an EPIC examination centre that was, on average, a greater distance for them. In Greece, the low participation rate (54.2\%) was largely due to logistic difficulties of approaching subjects living outside Athens.

Apart from The Netherlands and Greece, non-participation in the calibration sub-studies was due primarily to the subjects' failure or refusal to respond to the invitation or accept an appointment for the dietary interview ('active' non-response). This represents more than $20 \%$ of the total subjects approached in Sweden, France, Norway and the UK, with some variations across centres. In Spain for example, the active non-response rate ranged from $3.4 \%$ in Murcia to $24.7 \%$ in Granada. Overall, the active nonresponse was much lower when the subject was approached by surprise just after the main examination than when he/she was contacted afterwards. In Germany and Denmark the non-participation was exclusively active.

In contrast, in the Netherlands and Greece, 'passive' non-response (i.e. non-participation because it was impossible to get in touch with the subjects) was about the same as, or higher than, active non-response. In The Netherlands, this was because it was often impossible to contact subjects by phone and because staff at the baseline examination centre forgot to refer subjects to the dietitians. In Greece, the passive non-response rate was particularly 
high (30.5\%), which explains the overall low participation rate $(\sim 54 \%)$. Mobile units visited the areas outside Athens for short periods only and passive non-response was unavoidably high because of time constraints for approaching and interviewing subjects. In Norway, 15\% of the subjects approached could not be interviewed because of passive non-response.

\section{General characteristics and representativeness of the EPIC calibration sub-populations}

Tables 3-9 present a series of characteristics of the calibration sub-populations considered for analysis in this supplement. In addition, to estimate the representativeness of the calibration sub-populations, we compared these samples to the rest of the EPIC cohort according to certain variables known to influence dietary consumption. In order to take into account the differences in age distribution in the calibration samples, due to the agestratified sampling strategy, all of the results are presented age-adjusted. We tested for significant differences in weight, height and body mass index (BMI) mean estimates between the calibration samples and the rest of the EPIC population. Differences in smoking status, level of education and physical activity at work (categorical variables) were tested using gender- and centre-specific logistic regressions. We modelled the different categorical variables separately as independent covariates, an indicator for distinguishing the calibration sample from the rest of the cohort as a binary outcome, and age as an adjusting variable. Significance was assessed using likelihood ratio statistics, at 95\%, 99\% and 99.9\% levels. Analyses were performed using SAS software ${ }^{21}$. Since the main focus of this paper is the calibration sub-studies, the entire EPIC cohort, detailed elsewhere ${ }^{17,22-24}$, will be described only for the purpose of comparing the two population groups.

\section{Age and anthropometry}

The calibration sample is composed of middle-aged populations, from $49.3 \pm 4.3$ years (Norway) to $58.6 \pm 8.4$ years (Sweden) in women, and from $50.0 \pm 7.4$ years (Bilthoven) to $61.1 \pm 7.3$ years (Sweden) in men (Tables $3 \mathrm{a}$ and $3 \mathrm{~b}$ ). Anthropometry varies considerably across countries. Height adjusted for age is about $9-10 \mathrm{~cm}$ higher for women in Norway than in Spain and for men in Sweden than in Spain. The same order of difference $(\sim 10 \mathrm{~kg})$ is observed for weight among women in France and Greece, whereas a difference in weight of only $5.5 \mathrm{~kg}$ is observed in men between Italy and The Netherlands. Spain and Greece report both the lowest heights and the highest BMI in women and men, whereas Italy, The Netherlands, Germany, the UK general population, Sweden and Denmark report about the same BMI in women $\left(25-26 \mathrm{~kg} \mathrm{~m}^{-2}\right)$ and men $\left(26-27 \mathrm{~kg} \mathrm{~m}^{-2}\right)$. The lowest BMI $\left(\leq 24 \mathrm{~kg} \mathrm{~m}^{-2}\right)$ is observed in the Norwegian female cohort and in highly selected study populations such as women teachers in France and 'health-conscious' people in the UK.

When compared with the rest of the EPIC cohort, the weight, height and BMI means of the calibration populations showed statistically significant differences in $20-30 \%$ of the sex-specific centres. However, in centres where there was a statistically significant difference, this was usually modest in absolute terms. In most cases, the mean BMI differed between the calibration population and the entire cohort for centres where a statistically significant difference was observed for weight and/or height.

\section{Smoking status}

In this calibration population, the number of neversmokers is about 1.2-2.7 times higher in women than men. For women in Greece, Spain, France and the UK 'health-conscious' group, never-smokers represent $\geq 65 \%$ of the population (Table 4) and about 35-60\% elsewhere. In men, never-smokers represent $24-46 \%$. The percentage of ex-smokers varies to a greater extent among women (7-33\%) than among men (28-46\%), as does the percentage of smokers, from less than $9 \%$ to $\sim 25 \%$ for women and from $21 \%$ to $40 \%$ for men, except in the UK $(\sim 17 \%)$.

In about a quarter of the EPIC centres, the smoking status is not equally distributed between the calibration sub-sample and the entire EPIC cohort. Most of the imbalance is due, however, to differences of only a few percentage points $(<5 \%)$ across classes. Apart from the Spanish centres, the number of current smokers is equal or lower in the calibration sample than in the entire cohort. In contrast, the number of ex-smokers is higher in the calibration population, except in Umeå and for men in Spain. The number of never-smokers is relatively lower in the calibration sample in women from southern centres (France North-west, Navarra and Greece) whereas it tends to be higher in central and Nordic centres. In men, neversmokers are always equal or over-sampled in the calibration group compared with the entire cohort.

\section{Level of education}

A common variable in five classes of level of education was used in EPIC (Tables 5a and 5b). In Malmö, however, where the cohort was recruited before joining EPIC, the education level of 7332 subjects ( $\sim 25 \%$ of the total cohort) was defined differently and these subjects were therefore classified in the closest existing EPIC category (corresponding to 'technical school'). Large differences are observed in education level reflecting gender discrepancies and the diversity of origin of the cohorts (general population, blood donors, teachers and 'health-conscious' group $)^{17}$. For example, the number of subjects who never completed primary school is high in Spain, particularly among women and in the south, and Greece, whereas it is 


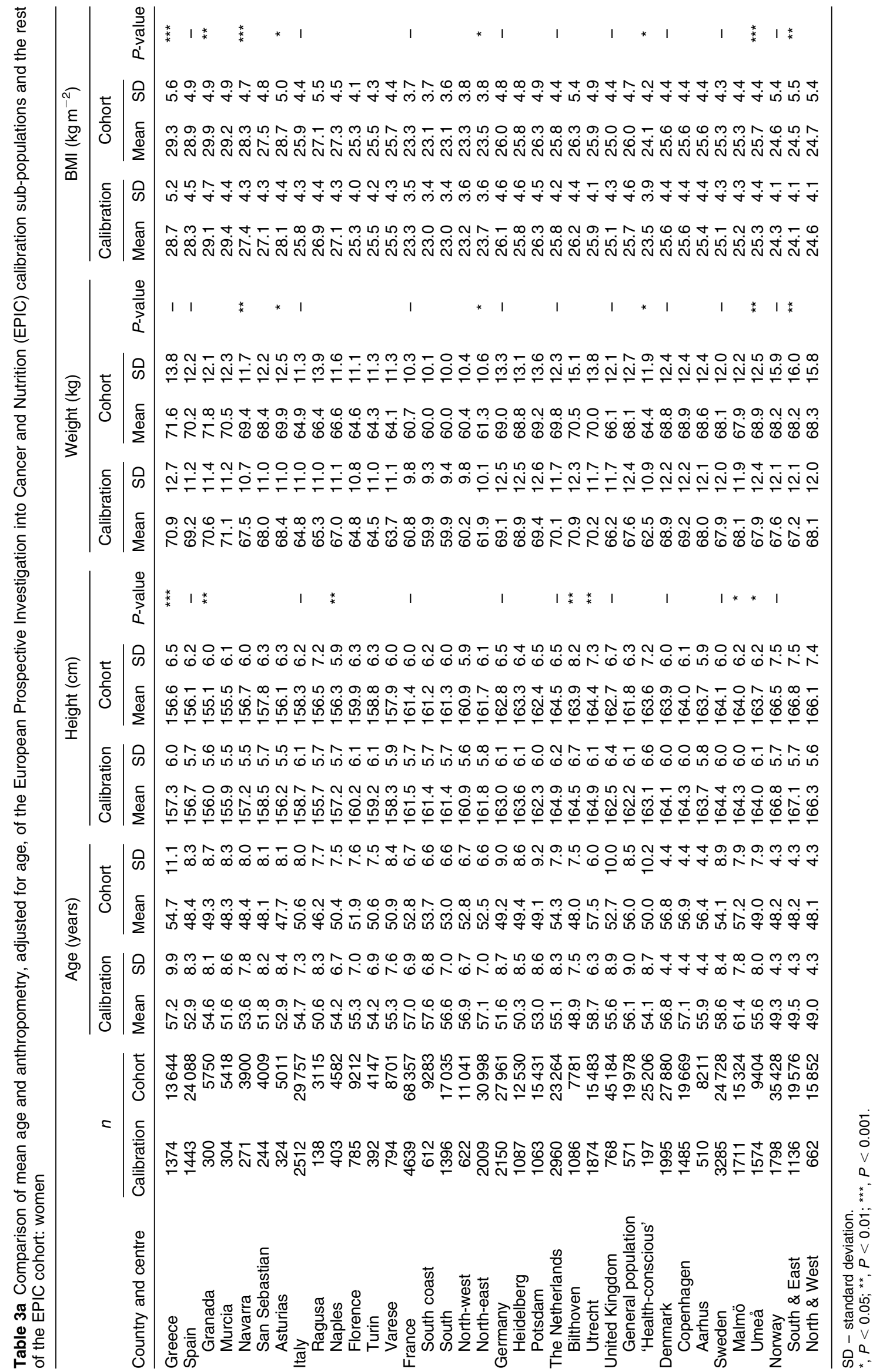




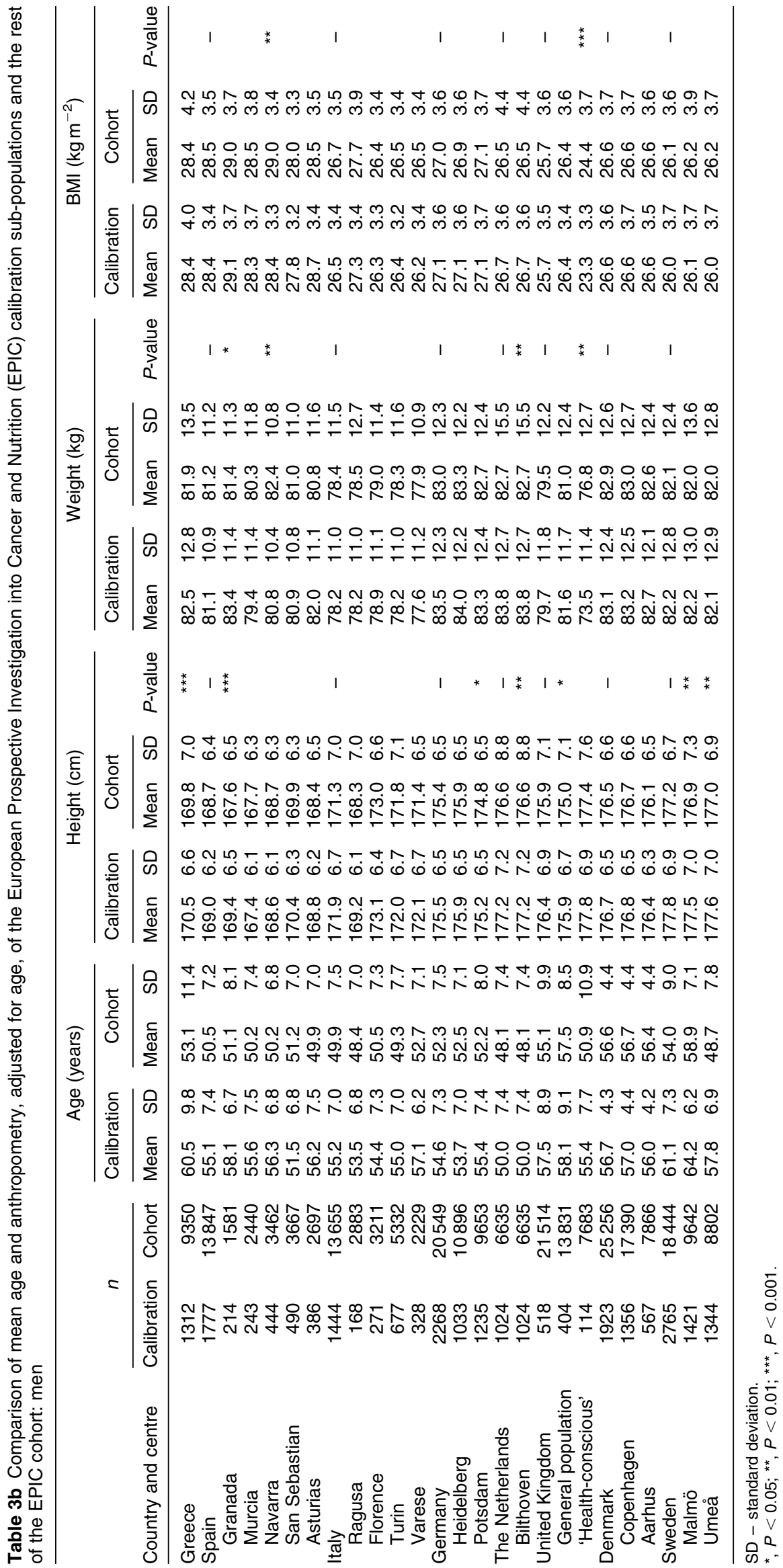




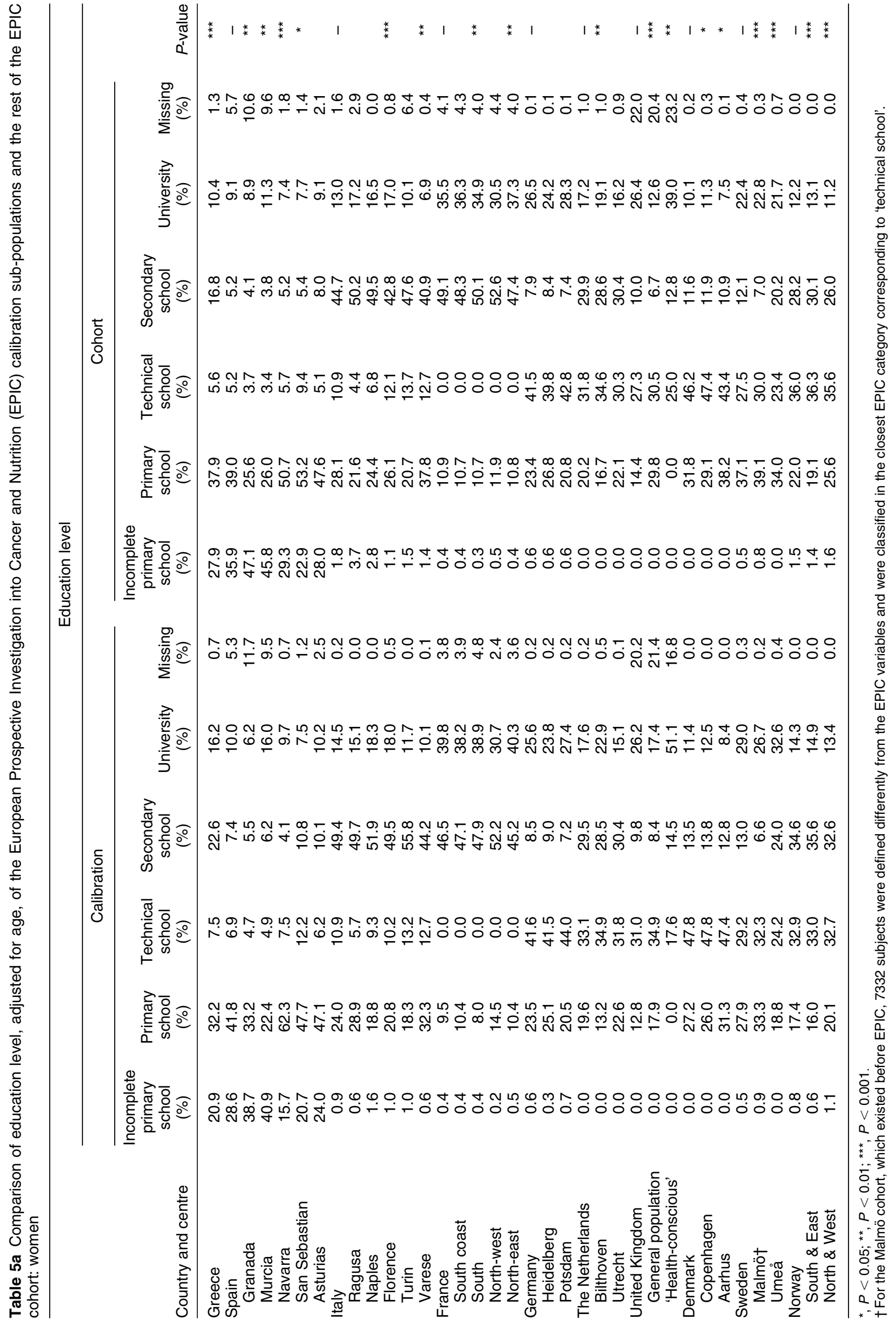



主

NN 近

. 他

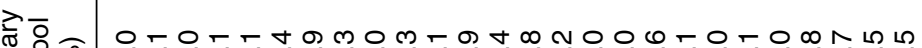

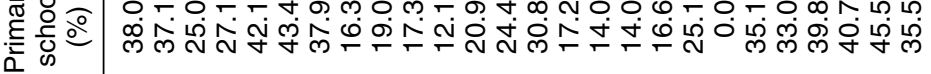

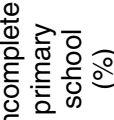

n $\infty$ n

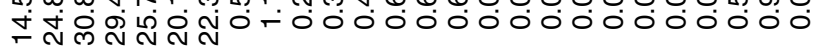

कृ 少 $\frac{\sqrt{5}}{\sqrt{n}}$

क อ ๓

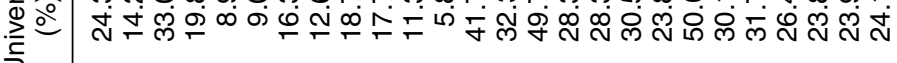
荅

O

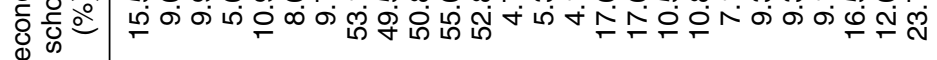

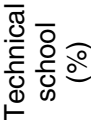
オ 슨

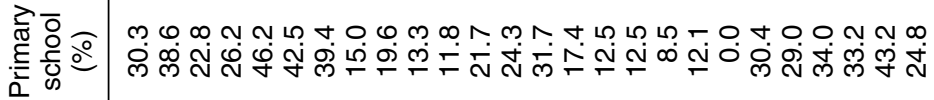

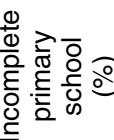

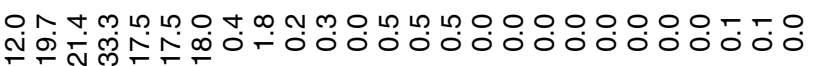




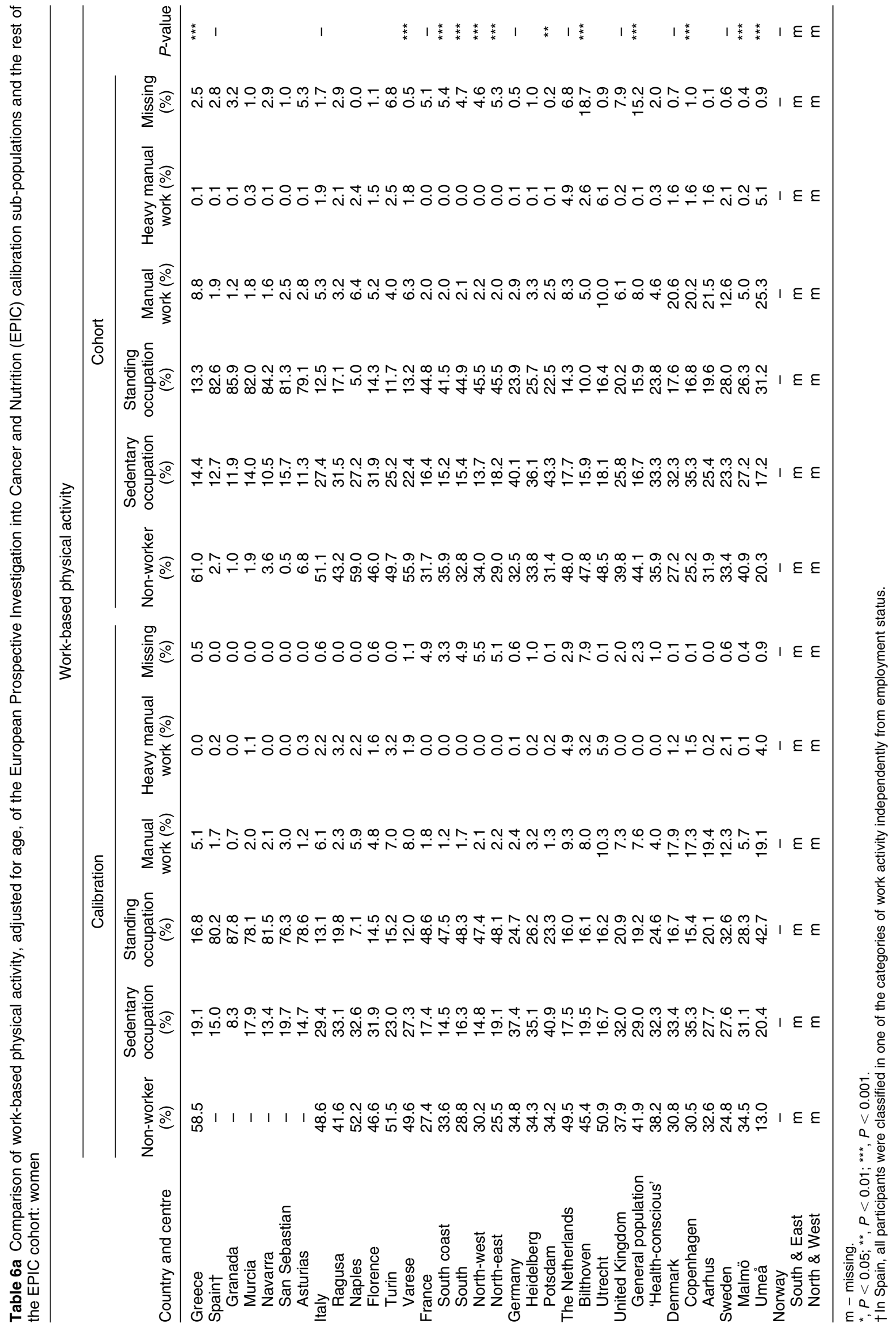




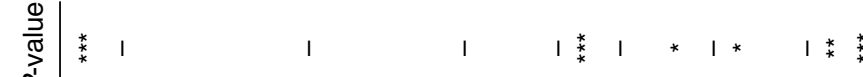

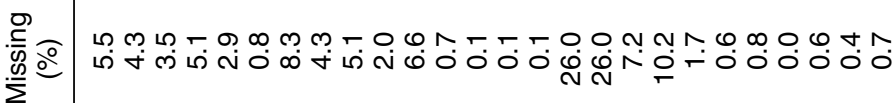
$\frac{\pi}{2}$

ฮั

交

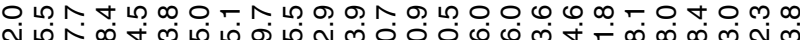

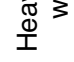

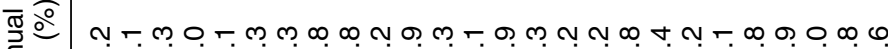
$\sum \xi$

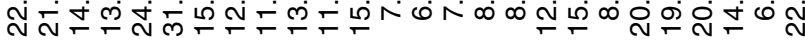

은으

으. फ ठ

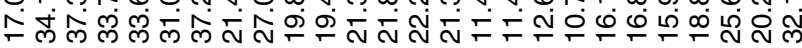

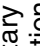

m

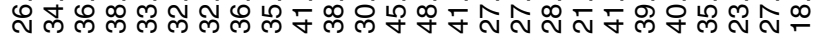
œ :

ब⿳亠口冋

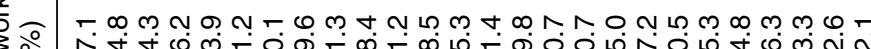
टे

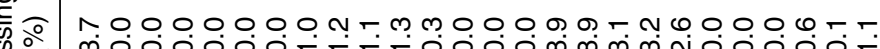
$\overline{\widetilde{\sigma}}$

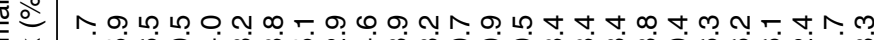
赵 - ம் 王

- - 0 t จ่

옫드

응

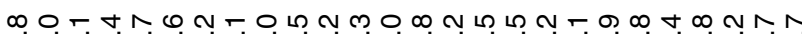

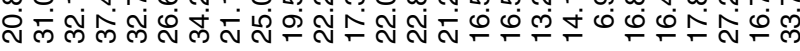
离章

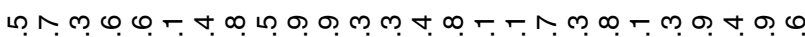

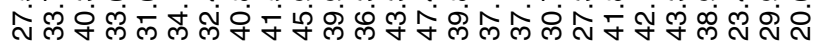

¿্য

产 은

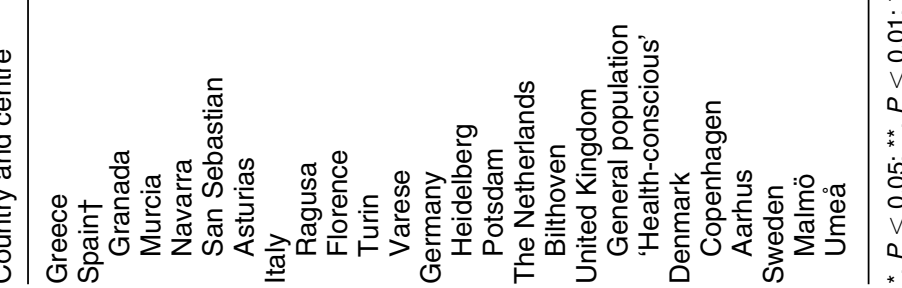


Table 7 Number, percentage and type of special diets reported in the European Prospective Investigation into Cancer and Nutrition (EPIC) calibration sub-populations

\begin{tabular}{|c|c|c|c|c|c|c|c|c|c|c|c|c|}
\hline \multirow[b]{3}{*}{ Country and centre } & \multicolumn{6}{|c|}{ Women } & \multicolumn{6}{|c|}{ Men } \\
\hline & \multicolumn{2}{|c|}{$\begin{array}{l}\text { Reported } \\
\text { special } \\
\text { diet }\end{array}$} & \multicolumn{4}{|c|}{$\begin{array}{l}\text { Type of special } \\
\text { diet reported }\end{array}$} & \multicolumn{2}{|c|}{$\begin{array}{l}\text { Reported } \\
\text { special } \\
\text { diet }\end{array}$} & \multicolumn{4}{|c|}{$\begin{array}{l}\text { Type of special } \\
\text { diet reported }\end{array}$} \\
\hline & $n$ & $\%$ & $\begin{array}{l}\text { Obesity } \\
(\%)\end{array}$ & $\begin{array}{c}\text { Vegetarian* } \\
(\%)\end{array}$ & $\begin{array}{l}\text { Diseases } \\
(\%)\end{array}$ & $\begin{array}{l}\text { Other } \\
(\%)\end{array}$ & $n$ & $\%$ & $\begin{array}{l}\text { Obesity } \\
(\%)\end{array}$ & $\begin{array}{c}\text { Vegetarian* } \\
(\%)\end{array}$ & $\begin{array}{l}\text { Diseases } \\
(\%)\end{array}$ & $\begin{array}{c}\text { Other } \\
(\%)\end{array}$ \\
\hline Greece & 424 & 29.3 & 4.1 & 0.4 & 20.2 & 4.6 & 382 & 27.8 & 1.2 & 0.3 & 21.0 & 5.3 \\
\hline Spain & 306 & 20.5 & 5.6 & 0.1 & 12.1 & 2.7 & 300 & 16.4 & 1.5 & 0.1 & 12.2 & 2.7 \\
\hline Granada & 75 & 23.4 & 3.8 & 0.0 & 15.0 & 4.7 & 60 & 26.4 & 2.6 & 0.4 & 18.5 & 4.9 \\
\hline Murcia & 49 & 15.5 & 5.7 & 0.3 & 7.3 & 2.2 & 24 & 9.8 & 1.2 & 0.0 & 6.5 & 2.0 \\
\hline Navarra & 52 & 19.0 & 5.5 & 0.0 & 11.7 & 1.8 & 95 & 21.0 & 1.1 & 0.0 & 18.4 & 1.6 \\
\hline San Sebastian & 24 & 9.8 & 2.9 & 0.0 & 4.5 & 2.5 & 30 & 6.1 & 0.8 & 0.0 & 2.4 & 2.8 \\
\hline Asturias & 106 & 31.0 & 9.1 & 0.0 & 19.6 & 2.3 & 91 & 22.2 & 2.4 & 0.0 & 16.9 & 2.9 \\
\hline Italy & 434 & 16.9 & 6.3 & 0.2 & 7.5 & 3.0 & 134 & 9.2 & 1.7 & 0.3 & 5.8 & 1.4 \\
\hline Ragusa & 11 & 8.0 & 4.4 & 0.0 & 0.7 & 2.9 & 7 & 4.1 & 1.2 & 0.0 & 1.8 & 1.2 \\
\hline Naples & 96 & 23.4 & 11.7 & 0.5 & 8.5 & 2.7 & - & - & - & - & - & - \\
\hline Florence & 136 & 16.9 & 6.3 & 0.4 & 8.7 & 1.5 & 32 & 11.6 & 1.5 & 0.7 & 8.3 & 1.1 \\
\hline Turin & 45 & 11.4 & 4.8 & 0.0 & 4.3 & 2.3 & 54 & 7.9 & 2.2 & 0.4 & 4.3 & 1.0 \\
\hline Varese & 146 & 18.0 & 4.6 & 0.0 & 8.4 & 5.1 & 41 & 12.5 & 1.2 & 0.0 & 8.8 & 2.4 \\
\hline France & 1129 & 23.8 & 5.7 & 0.4 & 14.4 & 3.3 & - & - & - & - & - & - \\
\hline South coast & 176 & 28.0 & 7.6 & 0.2 & 17.0 & 3.2 & - & - & - & - & - & - \\
\hline South & 251 & 17.8 & 3.1 & 0.4 & 10.8 & 3.5 & - & - & - & - & - & - \\
\hline North-west & 213 & 32.6 & 3.8 & 0.3 & 22.6 & 5.8 & - & - & - & - & - & - \\
\hline North-east & 489 & 23.8 & 7.6 & 0.6 & 13.3 & 2.3 & - & - & - & - & - & - \\
\hline Germany & 432 & 19.7 & 3.0 & 2.1 & 13.5 & 1.1 & 528 & 22.4 & 2.2 & 1.0 & 18.2 & 1.0 \\
\hline Heidelberg & 245 & 22.1 & 2.8 & 3.6 & 15.3 & 0.4 & 240 & 22.5 & 2.1 & 2.1 & 18.2 & 0.2 \\
\hline Potsdam & 187 & 17.2 & 3.1 & 0.6 & 11.7 & 1.8 & 288 & 22.2 & 2.2 & 0.2 & 18.2 & 1.6 \\
\hline The Netherlands & 680 & 22.4 & 5.9 & 0.5 & 11.1 & 4.9 & 72 & 7.0 & 1.2 & 0.0 & 3.8 & 2.0 \\
\hline Bilthoven & 129 & 11.7 & 3.2 & 0.5 & 5.0 & 3.1 & 72 & 7.0 & 1.2 & 0.0 & 3.8 & 2.0 \\
\hline Utrecht & 551 & 28.4 & 7.4 & 0.5 & 14.5 & 6.0 & - & - & - & - & - & - \\
\hline United Kingdom & 318 & 39.4 & 2.6 & 17.2 & 12.4 & 7.2 & 158 & 29.7 & 0.9 & 18.2 & 7.7 & 2.8 \\
\hline General population & 155 & 26.3 & 2.7 & 1.5 & 13.2 & 8.8 & 56 & 13.6 & 0.7 & 2.0 & 8.3 & 2.7 \\
\hline 'Health-conscious' & 163 & 75.1 & 2.3 & 59.9 & 10.1 & 2.8 & 102 & 84.3 & 1.7 & 73.6 & 5.8 & 3.3 \\
\hline Denmark & 242 & 12.0 & 2.1 & 0.2 & 8.8 & 1.0 & 146 & 7.6 & 0.9 & 0.0 & 6.3 & 0.3 \\
\hline Copenhagen & 200 & 13.3 & 1.5 & 0.2 & 10.4 & 1.3 & 123 & 9.0 & 0.8 & 0.0 & 7.8 & 0.4 \\
\hline Aarhus & 42 & 8.2 & 4.1 & 0.0 & 3.9 & 0.2 & 23 & 4.1 & 1.2 & 0.0 & 2.8 & 0.0 \\
\hline Sweden & 1073 & 31.2 & 0.8 & 0.8 & 22.4 & 7.2 & 729 & 25.5 & 0.7 & 0.2 & 19.0 & 5.5 \\
\hline Malmö & 382 & 22.0 & 0.1 & 0.6 & 11.8 & 9.5 & 242 & 16.9 & 0.4 & 0.4 & 8.5 & 7.6 \\
\hline Umeå & 691 & 40.6 & 1.5 & 1.0 & 33.3 & 4.9 & 487 & 34.1 & 1.1 & 0.1 & 29.6 & 3.4 \\
\hline Norway & 359 & 19.2 & 1.5 & 0.8 & 13.5 & 3.4 & - & - & - & - & - & - \\
\hline South \& East & 233 & 19.7 & 1.7 & 1.1 & 13.3 & 3.6 & - & - & - & - & - & - \\
\hline North \& West & 126 & 18.4 & 1.2 & 0.3 & 13.7 & 3.2 & - & - & - & - & - & - \\
\hline
\end{tabular}

* 'Vegetarian' includes vegans, ovo-lacto vegetarians and fish eaters (no meat eaters).

zero in the other countries and centres. In contrast, in Italy and France about half of the population, and a third in The Netherlands (women), have a secondary school diploma, and $40-50 \%$ of the UK 'health-conscious' group, French women teachers and men in Germany have a university degree.

In more than half of the centres, the distribution according to level of education is not strictly comparable between the calibration and the entire EPIC cohort populations. In certain centres, this difference is due to a few percentage-point differences in distribution across six classes. However, a quite consistent systematic tendency to under-represent the lowest education level classes (i.e. incomplete primary school and primary school) and to over-represent secondary and particularly university is observed.

\section{Work-based physical activity}

The subjects were asked to report their professional physical activities using a variable in four categories (sedentary, standing, manual work and heavy manual work $)^{23,25}$. In Malmö, subjects were asked about their physical activity at work as typical professional activity without referring to current occupational status, and a different physical activity questionnaire was used in Norway that was therefore not included in the analysis. In Spain, all participants were classified in one of the categories of work activity independently of employment status, so these variables are not directly comparable with the professional activities reported elsewhere ${ }^{23}$. These differences should not, however, affect the comparison of the calibration sub-sample with the entire cohort because the statistical analysis was stratified by centre. 
Table 8 Characteristics of the 24-hour dietary recall measurements

\begin{tabular}{|c|c|c|c|c|c|c|c|c|c|}
\hline \multirow[b]{2}{*}{ Country and centre } & \multirow[b]{2}{*}{$n$} & \multicolumn{2}{|c|}{$\begin{array}{l}\text { Time interval } \\
\text { between dietary } \\
\text { measurements } \\
\text { (months) }{ }^{\star}\end{array}$} & \multicolumn{2}{|c|}{$\begin{array}{l}\text { Time period } \\
\text { recalled } \\
\text { (hours) } †\end{array}$} & \multicolumn{2}{|c|}{$\begin{array}{l}\text { Interview } \\
\text { duration } \\
\text { (minutes) }\end{array}$} & \multicolumn{2}{|c|}{$\begin{array}{l}\text { Number } \\
\text { of food items } \\
\text { reported } \neq\end{array}$} \\
\hline & & Mean & SD & Mean & SD & Mean & SD & Mean & SD \\
\hline Greece & 2686 & 23.7 & 13.7 & 24.1 & 0.8 & 27 & 16 & 15.3 & 5.3 \\
\hline Spain & 3220 & 24.9 & 10.4 & 24.1 & 1.2 & 31 & 10 & 26.2 & 7.2 \\
\hline Granada & 514 & 27.0 & 12.9 & 24.0 & 0.8 & 31 & 11 & 27.2 & 6.9 \\
\hline Murcia & 547 & 21.3 & 8.7 & 24.0 & 1.1 & 26 & 8 & 26.5 & 7.3 \\
\hline Navarra & 715 & 31.1 & 7.1 & 24.1 & 1.3 & 34 & 9 & 25.3 & 6.2 \\
\hline San Sebastian & 734 & 19.5 & 9.1 & 24.1 & 1.4 & 30 & 10 & 28.5 & 7.1 \\
\hline Asturias & 710 & 25.6 & 9.9 & 24.1 & 1.1 & 34 & 10 & 23.7 & 7.4 \\
\hline Italy & 3956 & 20.1 & 12.4 & 24.1 & 0.9 & 29 & 11 & 25.0 & 6.9 \\
\hline Ragusa & 306 & 21.3 & 10.0 & 24.0 & 0.9 & 22 & 7 & 22.2 & 6.0 \\
\hline Naples & 403 & 34.2 & 11.7 & 24.0 & 0.9 & 27 & 10 & 21.3 & 5.9 \\
\hline Florence & 1056 & 16.9 & 15.7 & 24.0 & 0.9 & 28 & 10 & 24.6 & 6.1 \\
\hline Turin & 1069 & 19.4 & 9.2 & 24.1 & 1.1 & 33 & 10 & 28.7 & 7.5 \\
\hline Varese & 1122 & 18.6 & 8.5 & 24.1 & 0.9 & 30 & 13 & 23.9 & 6.2 \\
\hline France & 4639 & 31.7 & 9.3 & 24.1 & 0.9 & 29 & 11 & 27.2 & 6.7 \\
\hline South coast & 612 & 32.1 & 8.1 & 24.1 & 0.8 & 33 & 13 & 27.5 & 7.1 \\
\hline South & 1396 & 27.5 & 8.9 & 24.1 & 0.9 & 26 & 8 & 26.2 & 6.3 \\
\hline North-west & 622 & 33.2 & 8.9 & 24.1 & 0.9 & 32 & 9 & 28.5 & 6.8 \\
\hline North-east & 2009 & 34.1 & 8.9 & 24.1 & 0.9 & 30 & 11 & 27.3 & 6.7 \\
\hline Germany & 4418 & 0.5 & 1.8 & 24.0 & 1.1 & 35 & 17 & 23.2 & 6.3 \\
\hline Heidelberg & 2120 & 1.0 & 2.1 & 24.0 & 1.2 & 35 & 15 & 23.4 & 6.6 \\
\hline Potsdam & 2298 & -0.1 & 1.2 & 24.1 & 1.1 & 36 & 18 & 23.0 & 6.1 \\
\hline The Netherlands & 3984 & 0.5 & 1.5 & 24.1 & 1.2 & 33 & 12 & 27.7 & 7.7 \\
\hline Bilthoven & 2110 & 0.2 & 0.5 & 24.0 & 1.3 & 31 & 13 & 26.7 & 7.7 \\
\hline Utrecht & 1874 & 0.9 & 2.1 & 24.2 & 1.0 & 35 & 10 & 28.9 & 7.6 \\
\hline United Kingdom & 1286 & 12.4 & 11.0 & 24.1 & 0.8 & 39 & 20 & 30.4 & 8.3 \\
\hline General population & 975 & 11.9 & 10.8 & 24.2 & 0.8 & 37 & 17 & 30.8 & 8.1 \\
\hline 'Health-conscious' & 311 & 13.9 & 11.5 & 24.0 & 0.5 & 43 & 28 & 28.8 & 8.7 \\
\hline Denmark & 3918 & 0.1 & 0.5 & 24.0 & 1.2 & 27 & 11 & 24.1 & 7.0 \\
\hline Copenhagen & 2841 & 0.1 & 0.5 & 24.0 & 1.2 & 27 & 11 & 23.5 & 6.9 \\
\hline Aarhus & 1077 & 0.1 & 0.4 & 24.0 & 1.2 & 25 & 11 & 25.5 & 7.0 \\
\hline Sweden & 6050 & 34.1 & 16.0 & 24.1 & 1.2 & 33 & 13 & 25.3 & 7.1 \\
\hline Malmö & 3132 & 30.0 & 14.9 & 24.0 & 1.1 & 31 & 12 & 24.9 & 7.2 \\
\hline Umeå & 2918 & 38.5 & 15.9 & 24.1 & 1.3 & 35 & 14 & 25.7 & 7.0 \\
\hline Norway & 1798 & 12.8 & 3.5 & 24.0 & 1.6 & 30 & 12 & 23.3 & 6.4 \\
\hline South \& East & 1136 & 12.8 & 3.5 & 24.0 & 1.6 & 31 & 13 & 23.5 & 6.6 \\
\hline North \& West & 662 & 12.9 & 3.5 & 24.0 & 1.6 & 30 & 11 & 22.9 & 6.1 \\
\hline
\end{tabular}

SD - standard deviation.

* Time interval between baseline dietary assessment and 24-hour diet recall measurements.

† Mean time period covered from wake-up on the recalled day to wake-up on the following day.

$\neq$ Food + recipe items.

Except Denmark, Italy and The Netherlands $(\leq 20 \%)$ in men only, all countries report a relatively high proportion of subjects with no professional physical activity, particularly women (Tables 6a and 6b). EPIC cohorts have overall moderate professional physical activities, with predominantly sedentary or standing occupations, but a higher proportion of men with manual or heavy manual jobs and a lower number of non-workers compared with women is consistently observed in all EPIC cohorts.

The distribution of professional activities shows statistical differences between the calibration group and the entire EPIC cohorts for about $40 \%$ of the sex-specific centres. We consistently observed a tendency to undersample non-workers in most centres and both genders and to over-sample people with a sedentary and/or standing occupation. A more comparable distribution is, however, observed between the study groups when sedentary plus standing and manual plus heavy manual activities are grouped together. In Bilthoven and the UK 'healthconscious' group, the discrepancies observed are mainly due to a higher completeness of the calibration (i.e. lower number of missing values) compared with the entirecohort data.

\section{Special diet}

The number of study subjects who reported having a special diet during the 24-HDR interview was higher among women (12-39.4\%) than among men (7-29.7\%) (Table 7). Apart from the UK 'health-conscious' group, long-term health problems related to diet (e.g. hyperlipidaemia, hypertension, diabetes, stomach or intestinal problems) were the main reason given to explain their usual dietary habits, particularly in Umeå and, to a lesser 
Table 9 Day-to-day and seasonal distribution obtained in the European Prospective Investigation into Cancer and Nutrition (EPIC) calibration sub-studies

\begin{tabular}{|c|c|c|c|c|c|c|c|c|c|c|c|}
\hline \multirow[b]{2}{*}{ Country and centre } & \multicolumn{7}{|c|}{ Day of the week } & \multicolumn{4}{|c|}{ Season } \\
\hline & $\begin{array}{c}\text { Monday } \\
(\%)\end{array}$ & $\begin{array}{c}\text { Tuesday } \\
(\%)\end{array}$ & $\begin{array}{c}\text { Wednesday } \\
(\%)\end{array}$ & $\begin{array}{c}\text { Thursday } \\
(\%)\end{array}$ & $\begin{array}{c}\text { Friday } \\
(\%)\end{array}$ & $\begin{array}{l}\text { Saturday } \\
(\%)\end{array}$ & $\begin{array}{c}\text { Sunday } \\
(\%)\end{array}$ & $\begin{array}{l}\text { Spring } \\
(\%)\end{array}$ & $\begin{array}{c}\text { Summer } \\
(\%)\end{array}$ & $\begin{array}{l}\text { Autumn } \\
(\%)\end{array}$ & $\begin{array}{c}\text { Winter } \\
(\%)\end{array}$ \\
\hline Greece & 14.4 & 14.5 & 15.4 & 15.0 & 12.6 & 13.1 & 15.0 & 36.1 & 6.5 & 25.9 & 31.5 \\
\hline Spain & 16.4 & 15.8 & 16.0 & 12.5 & 12.4 & 13.2 & 13.6 & 28.5 & 26.5 & 20.6 & 24.5 \\
\hline Granada & 21.6 & 20.4 & 18.9 & 15.6 & 4.5 & 6.6 & 12.5 & 28.2 & 38.9 & 13.2 & 19.7 \\
\hline Murcia & 14.4 & 15.0 & 14.4 & 14.1 & 14.1 & 14.6 & 13.4 & 28.3 & 21.6 & 25.1 & 25.1 \\
\hline Navarra & 17.5 & 15.4 & 14.8 & 11.1 & 13.7 & 14.7 & 12.9 & 29.9 & 22.0 & 22.5 & 25.6 \\
\hline San Sebastian & 14.6 & 14.2 & 15.8 & 12.5 & 13.8 & 14.4 & 14.7 & 25.6 & 32.6 & 16.8 & 25.1 \\
\hline Asturias & 15.1 & 15.4 & 16.5 & 10.3 & 14.2 & 14.2 & 14.4 & 30.1 & 19.6 & 24.4 & 25.9 \\
\hline Italy & 16.0 & 16.5 & 16.4 & 15.6 & 11.2 & 10.2 & 14.3 & 30.5 & 18.1 & 25.4 & 26.0 \\
\hline Ragusa & 13.7 & 23.5 & 22.6 & 17.0 & 7.2 & 3.6 & 12.4 & 46.7 & 12.1 & 28.8 & 12.4 \\
\hline Naples & 18.4 & 13.9 & 20.6 & 17.1 & 6.0 & 7.9 & 16.1 & 22.3 & 8.9 & 15.9 & 52.9 \\
\hline Florence & 14.9 & 14.7 & 14.5 & 14.5 & 14.0 & 12.6 & 14.9 & 31.6 & 17.1 & 29.9 & 21.4 \\
\hline Turin & 15.4 & 16.0 & 15.3 & 16.8 & 12.3 & 9.3 & 14.9 & 32.5 & 22.4 & 19.5 & 25.7 \\
\hline Varese & 17.2 & 17.7 & 15.9 & 14.4 & 10.4 & 11.3 & 13.1 & 25.9 & 20.0 & 29.4 & 24.7 \\
\hline France & 18.6 & 18.3 & 17.1 & 15.5 & 8.3 & 11.2 & 11.1 & 34.5 & 13.0 & 22.7 & 29.8 \\
\hline South coast & 17.3 & 19.3 & 16.3 & 14.2 & 10.6 & 10.6 & 11.6 & 33.3 & 4.6 & 25.8 & 36.3 \\
\hline South & 17.8 & 17.5 & 16.9 & 16.8 & 8.0 & 11.7 & 11.5 & 37.7 & 16.3 & 22.3 & 23.8 \\
\hline North-west & 17.7 & 15.9 & 16.4 & 17.2 & 9.7 & 11.4 & 11.7 & 29.1 & 7.2 & 18.2 & 45.5 \\
\hline North-east & 19.8 & 19.2 & 17.7 & 14.4 & 7.4 & 10.9 & 10.6 & 34.3 & 15.2 & 23.5 & 27.1 \\
\hline Germany & 20.2 & 21.6 & 17.6 & 13.2 & 4.8 & 11.1 & 11.6 & 29.7 & 33.1 & 16.1 & 21.1 \\
\hline Heidelberg & 22.2 & 21.4 & 17.3 & 14.5 & 1.2 & 11.0 & 12.4 & 22.0 & 39.3 & 17.6 & 21.1 \\
\hline Potsdam & 18.3 & 21.8 & 17.8 & 12.1 & 8.1 & 11.1 & 10.8 & 36.9 & 27.4 & 14.7 & 21.1 \\
\hline The Netherlands & 15.2 & 15.3 & 14.7 & 13.6 & 13.0 & 13.8 & 14.5 & 24.6 & 30.6 & 22.8 & 22.0 \\
\hline Bilthoven & 15.9 & 16.5 & 14.7 & 13.3 & 11.4 & 13.7 & 14.6 & 26.3 & 28.9 & 24.3 & 20.6 \\
\hline Utrecht & 14.4 & 13.9 & 14.8 & 13.9 & 14.8 & 13.9 & 14.3 & 22.8 & 32.6 & 21.1 & 23.5 \\
\hline United Kingdom & 17.0 & 15.0 & 16.5 & 14.7 & 11.3 & 11.8 & 13.7 & 31.7 & 21.4 & 24.5 & 22.4 \\
\hline General population & 15.3 & 13.3 & 15.7 & 15.3 & 12.9 & 12.4 & 15.1 & 31.4 & 21.9 & 25.1 & 21.6 \\
\hline 'Health-conscious' & 22.5 & 20.3 & 19.0 & 12.9 & 6.1 & 10.0 & 9.3 & 32.8 & 19.9 & 22.5 & 24.8 \\
\hline Denmark & 19.5 & 21.4 & 16.6 & 14.9 & 8.3 & 8.7 & 10.8 & 22.8 & 12.7 & 24.6 & 40.0 \\
\hline Copenhagen & 18.5 & 23.2 & 16.7 & 15.2 & 8.2 & 7.7 & 10.4 & 25.8 & 12.9 & 21.2 & 40.1 \\
\hline Aarhus & 22.0 & 16.5 & 16.3 & 14.0 & 8.5 & 11.1 & 11.7 & 14.9 & 12.0 & 33.4 & 39.7 \\
\hline Sweden & 15.1 & 15.2 & 14.7 & 14.6 & 12.1 & 14.1 & 14.3 & 26.3 & 24.2 & 19.4 & 30.2 \\
\hline Malmö & 15.8 & 15.5 & 14.8 & 14.4 & 10.5 & 14.1 & 14.9 & 24.2 & 18.7 & 25.2 & 31.8 \\
\hline Umeå & 14.3 & 14.8 & 14.5 & 14.8 & 13.9 & 14.0 & 13.7 & 28.5 & 30.1 & 13.1 & 28.3 \\
\hline Norway & 16.9 & 17.2 & 17.0 & 12.3 & 7.7 & 11.4 & 17.5 & 25.8 & 13.5 & 30.3 & 30.5 \\
\hline South \& East & 17.3 & 17.5 & 17.5 & 13.4 & 6.9 & 10.3 & 17.2 & 25.1 & 13.3 & 30.6 & 31.1 \\
\hline North \& West & 16.3 & 16.6 & 16.2 & 10.4 & 9.2 & 13.1 & 18.1 & 26.9 & 13.8 & 29.8 & 29.6 \\
\hline
\end{tabular}

extent, Greece. Except in Sweden, the number of subjects who reported restricting their dietary intake because of overweight or obesity was in all centres $1.4-5$ times higher in women than in men. In the UK, $60 \%$ of the women and $74 \%$ of the men from the 'health-conscious' sample are vegans, ovo-lacto vegetarians or fish eaters who do not consume meat. The number of vegetarians in the other EPIC cohorts is $3.6 \%$ or lower.

\section{Logistics and methodological issues of the 24-hour dietary recall method}

Some of the characteristics of the reference dietary calibration method used are reported in Table 8.

\section{Time interval between baseline dietary assessment and 24-HDR measurements}

The time interval between dietary measurements varies from 1 day (or a few days) to several years. In The Netherlands, Germany and Denmark, most of the interviews were conducted at the same time as the baseline examination or shortly afterwards. In the UK, Italy, Greece and Spain, the interval between the two dietary measurements was between 12.4 and 25 months whereas in France, for logistic reasons, and Sweden, where the cohort existed before joining EPIC, the interval was as high as between 31.7 and 34.1 months.

\section{Duration of the recalled day}

The period to be covered during the recalled dietary interview was defined as the individual's time between waking up on the recalled day to waking up on the following day (interview day). This procedure was chosen instead of the time period from midnight to midnight to facilitate memory retrieval during the interview. Whatever the centre or country, the mean time interval was always about 24 hours.

\section{Interview duration}

The average duration of the 24-HDR interviews was $31.1 \pm 13.3 \mathrm{~min}$, and ranged from $27 \pm 11 \mathrm{~min}$ in Denmark to $39 \pm 20 \mathrm{~min}$ in the UK. The variations observed across 
centres may be explained by differences in dietary habits, total number of food items reported and the proportion of mixed recipes, which usually require more time to process than single food items. In the UK, the average duration was almost twice as high as the mean shortest interview time (22 $\pm 7 \mathrm{~min}$ in Ragusa), particularly among the 'health-conscious' study population ( $43 \pm 28 \mathrm{~min})$.

\section{Number of food items}

The mean number of items reported per interview varied twofold across countries, from $15.3 \pm 5.3$ (Greece) to $30.4 \pm 8.3$ (UK). However, when these two countries are disregarded, the total number of food items reported varied much less, $23.2 \pm 6.3$ in Germany to $27.2 \pm 6.7$ in France (women only). The variation between centres from the same country was small except for Turin (Italy) and Asturias (Spain) where the number of food items reported was, respectively, higher $(28.7 \pm 7.5)$ and lower $(23.7 \pm$ 7.4) than in the other local centres.

\section{Coverage of days of the week and seasons}

The optimal coverage of days of the week, particularly Fridays and Saturdays, was restricted both by a low participation rate for interviews performed during weekends and by the logistic problems of approaching and interviewing the subjects during non-working days. Table 9 shows that Fridays were highly under-represented in Germany (4.8\%), Norway (7.7\%), Denmark (8.3\%) and France (8.3\%), and far below the expected $14.3 \%$ corresponding to an equal distribution of the seven days of the week. For Saturdays, the under-sampling was much lower than for Fridays, except in Denmark (Copenhagen mainly) where it was below 9\%. This is probably because data concerning Saturdays were mostly collected on Mondays (i.e. during a working day) with a 48-hour time interval. In contrast, the interviews covering Fridays were always obtained during a weekend, Saturdays (24-hour interval) or Sundays (48-hour interval), which decreased the participation rate because of the logistic problems of interviewing subjects during non-working days. In the other countries, the same tendency to under-sample Fridays (and Saturdays) is observed, although to a lesser extent.

In certain countries, the interviews collected according to seasons tend to be under-sampled in summer and, to a lesser extent, autumn (Table 9). The 24-HDRs collected in summer were under-sampled by about 45-50\% (Denmark, France and Norway) and up to $70 \%$ in Greece. In the other countries, both under-sampling and over-sampling were observed but to a lesser degree. However, when the four seasons are grouped into two classes (spring/summer and autumn/winter), the coverage of seasons is much better balanced, except for Germany, where spring/summer tended to be over-sampled, whereas in Norway and Denmark it tended to be under-sampled by about $20-25 \%$.

\section{Discussion}

The EPIC calibration sub-studies were set up in order to improve the comparability of dietary data across the participating centres. The calibration concept imposes a number of requirements, which include the following:

1. Calibration sub-populations must be representative of the EPIC cohorts.

2. The common reference method for dietary intake assessment must provide correct estimates of mean population intakes.

3. Random errors in the reference measurements, i.e. variations not structurally related to subjects' true intake levels, must be statistically independent of (i.e. not correlated with) random errors in the dietary questionnaire assessments used for the full cohort.

For the above requirements to be met, much depends on practical, logistic and methodological issues. In order to obtain the necessary representative population, a high participation rate must be achieved from the individuals invited to take part in the calibration sub-study. In our studies, about $70 \%$ of the study centres reported a participation rate above $75 \%$. This response rate was consistently better when the subjects were recruited immediately after baseline examination than in centres where the subjects had to be re-invited at a later date. Important logistic constraints to re-approaching the subjects, as suggested by a high passive non-response rate, were observed in Greece and, to a lesser extent, in The Netherlands. It can be expected, however, that a passive non-response is random with regard to relevant subject characteristics.

Apart from study logistics, variations in the participation rates across study centres may also be partially explained by differences in social attitude and culture. In particular, the comparatively low response rates from representative samples of general populations (UK general population and Norway) or from an atypical population group (the 'health-conscious' group from Oxford) suggest that a number of other uncontrolled factors may determine the subjects' participation rate, as observed in the SENECA (Survey in Europe on Nutrition and the Elderly: a Concerted Action) study ${ }^{26}$.

The sampling procedures for the calibration sub-studies were stratified by age group and gender, and the sample size requirement was weighted by the expected numbers of cases of cancer in age-gender categories over 10 years of follow-up. This relative weighting will increase the precision of the statistical calibration procedure when it is used to correct relative risk estimates for biases induced by errors in the baseline dietary questionnaire assessments ${ }^{7,9}$. Within strata of age and gender, however, the aim was to obtain the participation of a random, fully representative sample of cohort members in the calibration studies.

In most centres, after adjustment for age, no significant 
differences in height, weight, BMI and smoking status were observed between the calibration sample and the rest of the individual cohort for either men or women. Greater differences were observed for level of education and physical activity. The large and heterogeneous study populations involved in the analysis may explain the higher likelihood of detecting statistically significant differences. Indeed, the actual differences observed were modest in most centres. However, we observed a slight tendency to under-represent current and never-smokers compared with ex-smokers and subjects with a low education level in the calibration sample, compared with the rest of the cohort. Non-workers were also underrepresented compared with sedentary and/or standing professional occupations in the calibration, compared with the cohort, in both genders. A higher completeness (i.e. a lower number of missing values) of the calibration compared with the entire cohort dataset also explains some differences between distributions, particularly for work-based physical activity in Bilthoven and the UK general population. Although most of the discrepancies in the distributions of these categorical variables were due to differences of only a few percentage points across classes, this might also suggest a possible selection/sampling bias that should not be completely disregarded, particularly in certain study centres.

In order to investigate further whether the observed differences in subjects' characteristics influence dietary estimates from the calibration sub-samples as representative of the entire cohort, we compared the centre mean dietary intakes obtained from the baseline dietary methods between the calibration and the rest of the cohort. Dietary intakes estimated from baseline assessment methods were used in this analysis because they were the only dietary measurements available from all of the EPIC study subjects (24-HDRs were collected from only $5-12 \%$ of the EPIC cohorts). The statistical analysis was stratified by centre in order to control for differences in baseline dietary methods used across EPIC and the dietary comparison was made for 16 main food groups, using the same EPIC-SOFT classification system across centres. Overall, $89 \%$ of the centre-sex-food group combinations considered show a mean difference of less than $\pm 10 \%$ (69\% had a difference within $\pm 5 \%$ ). However, $59 \%$ of the differences above $\pm 10 \%$ were observed in only four centres (UK 'healthconscious' group, Ragusa, Granada and Umeå) out of the 24 centres involved in this analysis. The UK 'healthconscious' sub-group alone represented about a quarter of these values, probably because of the low participation rate, the small size of the calibration sample and the lack of representativeness of the different sub-components of this group (i.e. vegans, vegetarians and fish eaters) compared with the rest of the 'health-conscious' cohort. For Granada and Umeå, the relatively low response rate $(\sim 70 \%)$ and statistically significant difference in distribution between the calibration and the rest of the cohort for anthropometric measurements (women in both centres), smoking status and physical activity at work (Umeå) suggest that they may not be strictly representative of the entire cohort, but further investigations are required. For Ragusa, no explanation was found to explain the systematic differences in mean estimates observed in about onethird of the combinations.

This analysis will be presented in greater detail elsewhere and further explanatory statistical analyses will consider the impact of imperfect representativeness of the calibration sub-samples observed in certain centres, particularly the 'health-conscious' group, when calibrating individual dietary questionnaire measurements.

Logistic constraints in performing interviews during weekends were reported in several EPIC countries. They were partially overcome by conducting interviews for Saturdays on Mondays, allowing a 48-hour time interval. However, this made it impossible to distinguish whether observed variations in average food intakes between Saturdays and other days of the week reflected the true differences or whether they were the result of bias because of the increased time elapsed (48 hours instead of 24), which may have affected the subjects' memory and capacity to report their diet. Fridays, for which interviews could only be performed during the weekend, were frequently under-sampled compared with the other days of the week. Collecting dietary interviews by telephone, using an adapted version of the EPIC-SOFT program as successfully experimented in Norway, may be a promising alternative to improve the coverage of all days of the week and seasons in future ${ }^{27}$. However, the practical difficulty of obtaining an equal distribution of 24-HDR according to days of the week and seasons, and the confirmation that a high day-to-day variation for different food groups such as meat, fish and alcohol exists ${ }^{28-30}$, suggests that adjustments for imperfect distributions of season and particularly day of the week are needed in statistical analyses on diet and when applying the calibration.

In most situations, the 24-HDRs were collected either at the time of baseline examination or after re-contacting the subjects. In several centres, cohorts existed before they joined the EPIC network. In other centres, where baseline recruitment had started relatively early, the calibration studies were initiated several years later because the EPICSOFT program had not yet been finalised. In these centres, subjects were re-contacted up to three years after their baseline examination and dietary questionnaire assessment. A somewhat longer time interval between the baseline dietary questionnaire assessment and 24-HDR for the calibration studies may have the advantage of reducing correlations between random errors of the two measurements, to the extent that such correlations depend on whether measurements were collected over a short interval of time. A disadvantage, however, is that over longer time intervals more subjects may have changed their diet because of age, development of disease, or other 
changes in life status. The calibration studies were set up to correct for between-centre differences in the effects of errors in the baseline dietary questionnaire assessments. This correction will have to rely on the assumption that changes in true mean intake level over time did not substantially affect the validity of the 24-HDR measurements for inferences about between-centre differences in subjects' true habitual intake level at the time of recruitment.

The time needed to perform the interviews with the EPIC-SOFT program ( $30 \mathrm{~min})$ was quite comparable across centres and compatible with the cost and logistic constraints of large nutritional studies. This includes both the time needed to perform the dietary interview and the automatic data entry. However, more time - varying across centres - was needed to update incomplete 24-hour dietary recalls after the interview. The degree of standardisation of 24-HDR measurements for use in calibration sub-studies has been reported elsewhere ${ }^{19}$. Overall, 24-HDR measurements were reasonably well standardised across the interviewers involved in the calibration studies, although within certain centres an interviewer or gender effect was observed. The extent of systematic underreporting associated with 24-HDR measurements and its main determinants, discussed elsewhere in this supplement, will give further insights into the relative validity of mean 24-HDR measurements ${ }^{31}$.

This was the first time that calibration sub-studies had been set up in a large multi-centre European study. These studies showed that, despite some inherent methodological and logistic constraints, such a study design works relatively well in practice and can provide valuable additional measurements for better interpreting results from multi-centre epidemiological studies on diet and risk of chronic disease. In addition, the overall results suggest that, after adjustment for age, the calibration samples are fairly representative of the entire group of cohorts and that dietary intakes estimated from these sub-samples should reasonably be interpreted as representative of the main cohorts in most of the EPIC centres.

\section{Acknowledgements}

The work described in this paper was carried out with financial support of the 'Europe Against Cancer Programme' of the European Commission (SANCO); Ligue contre le Cancer (France); Société 3M (France); Mutuelle Générale de l'Education Nationale; Institut National de la Santé et de la Recherche Médicale (INSERM); Institute Gustave Roussy; German Cancer Aid; German Cancer Research Centre; German Federal Ministry of Education and Research; Danish Cancer Society; Health Research Fund (FIS) of the Spanish Ministry of Health; the Spanish Regional Governments of Andalucia, Asturias, Basque Country, Murcia and Navarra; Cancer Research UK; Medical Research Council, UK; Stroke Association, UK;
British Heart Foundation; Department of Health, UK; Food Standards Agency, UK; Wellcome Trust, UK; Greek Ministry of Health; Greek Ministry of Education; Italian Association for Research on Cancer; Italian National Research Council; Dutch Ministry of Public Health, Welfare and Sports; Dutch Prevention Funds; LK Research Funds; Dutch ZON (Zorg Onderzoek Nederland); World Cancer Research Fund; Swedish Cancer Society; Swedish Scientific Council; Regional Government of Skane, Sweden; Norwegian Cancer Society; Norwegian Research Council. Partial support for the publication of this supplement was provided by the Centre de Recherche et d'Information Nutritionnelles (CERIN).

In addition, we wish to thank all study participants for their co-operation and all interviewers who participated in the fieldwork studies in each EPIC centre.

\section{References}

1 Willett W. Future research directions. In: Willett W, ed. Nutritional Epidemiology. New York: Oxford University Press, 1990; 380-5.

2 White E, Hunt JR, Casso D. Exposure measurement in cohort studies: the challenges of prospective data collection. Epidemiol. Rev. 1998; 20: 43-56.

3 Willett WC, Colditz GA. Approaches for conducting large cohort studies. Epidemiology 1998; 20: 91-9.

4 Prentice RL. Design issues in cohort studies. Stat. Meth. Med. Res. 1995; 4: 273-92.

5 Friedenreich CM. Methodologic issues for pooling dietary data. Am. J. Clin. Nutr. 1994; 59: S251-2.

6 Rosner B, Willett WC, Spiegelman D. Correction of logistic relative risk estimates and confidence intervals for systematic within-person measurement error. Stat. Med. 1989; 8 1051-69.

7 Plummer M, Clayton D, Kaaks R. Calibration in multi-centre cohort studies. Int. J. Epidemiol. 1994; 23: 419-26.

8 Kaaks R, Plummer M, Riboli E, Estève J, van Staveren WA Adjustment for bias due to errors in exposure assessments in multi-centre cohort studies on diet and cancer: a calibration approach. Am. J. Clin. Nutr. 1994; 59: S245-50.

9 Kaaks R, Riboli E, van Staveren WA. Calibration of dietary intake measurements in prospective cohort studies. Am. J. Epidemiol. 1995; 142: 548-56.

10 Kipnis V, Carroll RJ, Freedman LS, Li L. Implications of a new dietary measurement error model for estimation of relative risk: application to four calibration studies. Am.J. Epidemiol. 1999; 150: 642-51.

11 Thompson FE, Moler JE, Freedman LS, Clifford CK, Stables GJ, Willett WC. Register of dietary assessment calibrationvalidation studies: a status report. Am.J. Clin. Nutr. 1997; 65 S1142-7.

12 Stram DO, Hankin JH, Lynne R, Wilkens LR, Pike MC, Monroe KR, et al. Calibration of the dietary questionnaire for a multiethnic cohort in Hawaii and Los Angeles. Am. J. Epidemiol. 2000; 151: 358-70.

13 Riboli E, Elmståhl S, Saracci R, Gullberg B, Lindgärde F. The Malmö Food Study: validity of two dietary assessment methods for measuring nutrient intakes. Int. J. Epidemiol. 1997; 26: S161-71.

14 Overvad K, Tjønneland A, Haraldsdóttir J, Bang S, Ewertz, Møller-Jensen O. Development of a semi-quantitative food frequency questionnaire to assess food, energy and nutrient intake in Denmark. Int. J. Epidemiol. 1991; 20: 906-12.

15 Bingham SA, Gill C, Welch A, Day K, Cassidy A, Khaw KT, 
et al. Comparison of dietary assessment methods in nutritional epidemiology: weighted records v. $24 \mathrm{~h}$ recalls, food-frequency questionnaires and estimated-diet records. Br. J. Nutr. 1994; 72: 619-43.

16 Margetts BM, Pietinen P, Riboli E, eds. EPIC: European Prospective Investigation into Cancer and Nutrition: validity studies on dietary assessment methods [special issue]. Int. J. Epidemiol. 1997; 26(Suppl. 1): S1-189.

17 Riboli E, Hunt K, Slimani N, Ferrari P, Norat T, Fahey M, et al. European Prospective Investigation into Cancer and Nutrition (EPIC): study populations and data collection. Public Health Nutr. 2002; 5(6B): 1113-24.

18 Slimani N, Deharveng G, Charrondière RU, van Kappel AL, Ocké MC, Welch A, et al. Structure of the standardized computerized 24-hour diet recall interview used as reference method in the 22 centres participating in the EPIC project. Comput. Meth. Programs Biomed. 1999; 53: 251-66.

19 Slimani N, Ferrari P, Ocké M, Welch A, Boeing H, van Liere $\mathrm{M}$, et al. Standardization of the 24-hour diet recall calibration method used in the European Prospective Investigation into Cancer and Nutrition (EPIC): general concepts and preliminary results. Eur. J. Clin. Nutr. 2000; 54: 900-17.

20 Kaaks R, Riboli E, van Staveren W. Sample size requirements for calibration studies of dietary intake measurements in prospective cohort investigations. Am. J. Epidemiol. 1995; 142: $557-65$.

21 SAS Institute. SAS/STATR User's Guide Version 8. SAS Manual 4(6). Cary, NC: SAS Institute, 1999-2000.

22 Haftenberger M, Lahmann PH, Panico S, Gonzalez CA, Seidell JC, Boeing H, et al. Overweight, obesity and body fat distribution in 50- to 64-year-old participants in the European Prospective Investigation into Cancer and Nutrition (EPIC). Public Health Nutr. 2002; 5(6B): 1147-62.

23 Haftenberger M, Schuit AJ, Tormo MJ, Boeing H, Wareham $\mathrm{N}$, Bueno-de-Mesquita HB, et al. Physical activity of subjects aged 50-64 years involved in the European Prospective Investigation into Cancer and Nutrition (EPIC). Public Health Nutr. 2002; 5(6B): 1163-77.
24 Klipstein-Grobusch K, Slimani N, Krogh V, Keil U, Boeing H, Overvad K, et al. Trends in self-reported past alcoholic beverage consumption and ethanol intake from 1950 to 1995 observed in eight European countries participating to the European Investigation into Cancer and Nutrition (EPIC). Public Health Nutr. 2002; 5(6B): 1297-310.

25 Pols MA, Peeters PH, Ocké MC, Slimani N, Bueno-deMesquita HB, Collette HJA. Estimation of reproducibility and relative validity of the questions included in the EPIC physical activity questionnaires. Int. J. Epidemiol. 1997; 26: S181-9.

26 SENECA Investigators. Assessment of bias in the SENECA study. Eur. J. Clin. Nutr. 1996; 50(Suppl. 2): S4-8.

27 Brustad M, Skeie G, Braaten T, Slimani N, Lund E. Comparison of telephone versus face-to-face interview in the assessment of dietary intake by the 24-hour recall EPICSOFT programme - the Norwegian calibration study. Eur. J. Clin. Nutr. 2002; in press.

28 Linseisen J, Kesse E, Slimani N, Bueno-de-Mesquita BH, Ocké MC, Skeie G, et al. Meat consumption in the European Prospective Investigation into Cancer and Nutrition (EPIC) cohorts - results from 24-hour dietary recalls. Public Health Nutr. 2002; 5(6B): 1243-58.

29 Welch AA, Lund E, Amiano P, Dorronsoro M, Brustad M, Kumle M, et al. Variability of fish consumption within the 10 European countries participating in the European Prospective Investigation into Cancer and Nutrition (EPIC) study. Public Health Nutr. 2002; 5(6B): 1273-85.

30 Sieri S, Agudo A, Kesse E, Klipstein-Grobusch K, San-José B, Welch AA, et al. Patterns of alcohol consumption in 10 European countries participating in the European Prospective Investigation into Cancer and Nutrition (EPIC) project. Public Health Nutr. 2002; 5(6B): 1287-96.

31 Ferrari P, Slimani N, Ciampi A, Trichopoulos D, Naska A, Lauria C, et al. Evaluation of under- and overreporting of energy intake in the 24-hour diet recalls in the European Prospective Investigation into Cancer and Nutrition (EPIC). Public Health Nutr. 2002; 5(6B): 1329-45. 